\title{
VIOLÊNCIA SEXUAL E CONSUMO DE SUBSTÂNCIAS PSICOATIVAS: PODEM OS CONTEXTOS FESTIVOS SER EDUCATIVOS?
}

\section{Resumo}

Neste artigo, analisa-se a tríade sexo feminino, consumo de substâncias psicoativas em contextos festivos e a sua relação com situações de violência sexual. Através da revisão bibliográfica e de dois grupos de discussão realizados com frequentadoras de contextos festivos e utilizadoras recreativas de substâncias psicoativas $(n=12)$, com idades compreendidas entre os 16 e os 46 anos e de classe média, foram identificadas várias desigualdades de género que emergem em ambientes de diversão noturna. A normalização de situações de violência sexual nestes contextos e a reprodução de mitos da violação justificam a implementação de ações educativas informais que os previnam. Nesse sentido, analisam-se também propostas de intervenção que se têm focado nesse fenómeno sublinhando-se as boas práticas.

Palavras-chave: Violência sexual, substâncias psicoativas, contextos festivos, educação informal.

\begin{abstract}
Sexual violence and consumption of psychoactive substances: can the festive contexts be educational?

This paper analyses the triad feminine sex, drug use in party settings and its association with sexual violence. Through literature review and two focus groups implemented with female partygoers and recreational drug users $(n=12)$, aged between 16 and 46 years old and from middle class, several gender inequalities emerging in party settings were highlighted. The normalization of sexual violence in these settings and the reproduction of rape myths justify the implementation of informal educational interventions to prevent them. Considering this, responses to this phenomenon and best practices are also analyzed.
\end{abstract}

Keywords: Sexual violence, psychoactive substances, party settings, informal education.

* $\quad$ Centro em Rede de Investigação em Antropologia (CRIA) e Research on Education and Community Intervention (RECI), 4150-308 Porto, Portugal.

Endereço postal: CRIA — Av. Forças Armadas, Edifício ISCTE-IUL, sala 2W2, 1649-026 Lisboa. Portugal.

Endereço eletrónico: cris.vpires@gmail.com

** Centro em Rede de Investigação em Antropologia (CRIA), Instituto Superior das Ciências do Trabalho e das Empresas do Instituto Universitário de Lisboa (ISCTE-IUL), 1649-026 Lisboa, Portugal. Endereço eletrónico: raquelmmp@gmail.com

*** Faculdade de Psicologia e Ciências da Educação da Universidade do Porto (FPCE-UP) e Associação Kosmicare, 4000-148 Porto, Portugal.

Endereço eletrónico: Helenamvalente@gmail.com

**** Research on Education and Community Intervention (RECI) e Agência Piaget para o Desenvolvimento (APDES), 4150-077 Porto, Portugal.

Endereço eletrónico: helena.moura.carvalho@gmail.com 


\begin{abstract}
Resumen
Violencia sexual y el consumo de sustancias psicoactivas: ¿pueden los contextos festivos ser educativos?

En este artículo, analizase la tríada sexo femenino, consumo de sustancias psicoactivas en contextos de ocio nocturno y su relación con violencia sexual. A través de la revisión bibliográfica y de dos grupos de discusión, realizados con frecuentadoras de contextos de ocio nocturno y usuarias recreativas de sustancias psicoactivas $(n=12)$, con edades comprendidas entre los 12 e los 46 años e de clase media, se identificaron varias desigualdades de género que emergen en ambientes de ocio nocturno. La normalización de situaciones de violencia sexual y la reproducción de mitos de violación en estos contextos justifican la implementación de acciones educativas informales que los prevengan. En este sentido, se analizan también algunas intervenciones que se han enfocado en este fenómeno y las buenas prácticas.
\end{abstract} mal.

Palabras clave: Violencia, sustancias psicoactivas, contextos festivos, educación infor-

\title{
Introdução
}

Este artigo propõe uma análise exploratória da tríade sexo feminino, consumo de substâncias psicoativas em contextos festivos (espaços-tempo e diversão noturna) e a sua relação com situações de violência sexual.

A Convenção do Conselho da Europa para a Prevenção e o Combate à Violência contra as Mulheres e a Violência Doméstica, habitualmente designada por Convenção de Istambul, concebe todas as formas de violência contra as mulheres como violência de género (Sottomayor 2015). As situações de violência que afetam desproporcionalmente as mulheres, reproduzem as relações de poder e de dominação das mulheres pelos homens foram identificadas, através desta Convenção, como violações graves dos direitos humanos das mulheres. Neste âmbito, a violência sexual inclui, não apenas as situações associadas a violência e coação grave, mas também os subvalorizados episódios de assédio sexual. «O assédio sexual deve ser sancionado penalmente porque constitui um comportamento que viola os direitos humanos das mulheres à liberdade, à integridade pessoal e ao livre desenvolvimento da personalidade» (Sottomayor 2015, 120). O assédio sexual diz respeito a situações de importunação sexual (verbal, não-verbal ou física) e é uma realidade presente em vários contextos da vida pública das mulheres (trabalho, rua, transportes públicos). Neste artigo, pretende-se demonstrar que, em contextos festivos, este tipo de violência sexual está naturalizado e é exacerbado por ser um contexto associado ao consumo de substâncias psicoativas (SPA), desinibição e interações sexualizadas.

A feminização dos contextos festivos, vivências e consumos associados não se traduziu numa maior simetria entre sexos em termos da vivência destes contextos. Para além de muitos contextos festivos promoverem ambientes sexistas, as mulheres frequentadoras de contextos festivos e utilizadoras de SPA são vistas como acessíveis e com maior disponibilidade sexual, desculpando e legitimando situações de assédio sexual. As normas hegemónicas de masculinidade de feminilidade 
surgem nestes contextos associadas a uma alarmante desigualdade de género, principalmente tendo em conta o risco de as mulheres poderem ser vítimas de violência sexual de maior ou menor intensidade (Noctambul@s 2016) e da reprodução de mitos de violação - crenças estereotipadas sobre violência sexual que normalmente resultam na culpabilização da vítima, por exemplo, por não se ter protegido ou por se ter exposto e na desculpabilização do agressor, p. ex., com base na impulsividade sexual masculina (Bohner et al. 2009). A este respeito, os resultados do Eurobarómetro da Violência de Género ${ }^{1}$ (TNS Opinion \& Social 2016), para além de outros dados alarmantes, demonstraram que um em cada 10 respondentes consideram que as relações sexuais não consentidas podem ser justificáveis em pelo menos uma destas situações «a vítima está embriagada ou sob o efeito de drogas» (12\% UE, 19\% Portugal) e «não dizer 'não `claramente ou não resistir fisicamente» (10\% UE, 10\% Portugal). As assimetrias de género e a naturalização de situações de violência sexual em contextos festivos devem ser contrariadas e intervencionadas, não apenas junto dos potenciais agressores, vítimas e espectadores (bystanders) mas também corresponsabilizando os/as promotores/as destes eventos.

\section{Metodologia}

A análise proposta resulta de um estudo exploratório que pretendeu levantar necessidades de intervenção ao nível da tríade sexo feminino, consumo de SPA em contextos festivos e violência sexual. Os resultados foram recolhidos através de revisão bibliográfica e de dois grupos de discussão focalizados realizados em Lisboa $(n=6)$ e em Viseu ( $n=6)$, cujo guião pretendia explorar as especificidades da frequência de contextos festivos e do consumo de SPA em mulheres portuguesas. A implementação de grupos de discussão nestas duas cidades em específico relacionou-se com o facto de aqui já estarem a ser implementados projetos de redução de riscos associados ao consumo de SPA em contextos festivos coordenados por duas das autoras deste artigo. Estes projetos ${ }^{2}$ - CHECK!N Lx e CHECK!N Viseu promovem um conjunto de ações de educação informal e não-formal junto de frequentadores/as de contextos festivos com o objetivo de reduzir os riscos associados ao consumo de substâncias psicoativas e sexualidade nestes contextos. Esta intervenção tem vindo a mostrar-se eficaz no seu objetivo de contribuir para a adoção de práticas de consumo de substâncias psicoativas mais seguras e saudáveis (Valente, Pires e Carvalho, 2018). Este estudo foi implementado com o objetivo de garantir que as atividades dos projetos fossem sensíveis ao género, incluindo esta dimensão na promoção de uma cultura de diversão noturna mais segura. Estes

Iniciativa promovida pela Direção-Geral para a Justiça e Consumidores da Comissão Europeia para aceder às perceções dos cidadãos e cidadãs Europeus/eias sobre violência de género.

Estes projetos são promovidos pela Agência Piaget para o Desenvolvimento (APDES) e cofinanciadas pelo Serviço de Intervenção nos Comportamentos Aditivos e Dependências (SICAD). 
grupos de discussão foram intencionalmente implementados com mulheres frequentadoras de contextos festivos e utilizadoras de álcool e/ou substâncias psicoativas (estes foram os dois critérios de inclusão), por se reconhecer que a maior parte da informação e intervenções de redução de riscos e promoção da saúde na área do consumo de SPA se foca nas experiências subjetivas de homens, excluindo as especificidades das mulheres. Apesar disso, é de notar que a maior parte das ações de prevenção de violência sexual em contextos festivos se focam nas potenciais vítimas e na importância destas se protegerem em vez de intervirem junto dos homens utilizadores (e não utilizadores) de SPA para que não agridam.

As participantes foram recrutadas em Lisboa e em Viseu pelas equipas dos projetos que disseminaram esta atividade no terreno e através da divulgação dos/as voluntários/as que apoiavam as intervenções. Após esta divulgação inicial, as mulheres que se mostraram disponíveis para participar foram contactadas para perceber se mantinham o interesse e para agendar os grupos de discussão. Em termos de caracterização sociodemográfica, os grupos foram heterogéneos em termos de idade, background socioeconómico e cultural (frequência de diferentes tipos de contextos festivos), manutenção ou não de relações amorosas e maternidade (3 participantes eram mães). Em Viseu, o grupo de discussão foi dinamizado com 6 frequentadoras de contextos festivos e utilizadoras de álcool com idades compreendidas entre os 16 e os 46 anos, das quais 4 eram estudantes (1 do Ensino Secundário e 3 do Ensino Superior) duas trabalhavam, uma das mulheres era mãe e outra estava grávida do/a seu/sua primeiro/a filho/a. Em Lisboa, as idades das 6 participantes variavam entre os 21 e os 43 anos. Todas estas mulheres trabalhavam, sendo que duas delas eram também estudantes do Ensino Superior. Com esta diversidade, procurou-se identificar a existência de sexismo e violência sexual de índole mais específico e/ ou transversal. Os grupos de discussão protegeram a identidade das participantes e por esse motivo as suas citações são identificadas através de um código - GD (grupo de discussão) cidade (Lisboa-Lx ou Viseu) Pn. ${ }^{\circ}$ (número da participante).

Finalmente, foi feita uma pesquisa online sobre campanhas e ações de índole educativa e preventiva de agressões sexuais relacionadas com o consumo de álcool e/ou outras SPA em contextos festivos, a avaliação da sua pertinência e boas práticas. Estas intervenções foram analisadas criticamente através de uma revisão bibliográfica que contemplou artigos e relatórios que apresentavam e discutiam resultados de intervenções já implementadas em contextos festivos.

\section{Apresentação dos resultados e discussão}

\section{Contextos festivos e (des)igualdades de género}

Vários autores têm definido contextos festivos como espaços-tempo privilegiados de lazer onde a diversão noturna se configura como uma quebra da rotina com a vida quotidiana, de socialização e de procura ativa de prazer (Hollands 
1995; Goulding e Shankar 2011). Esta valorização do lazer e da socialização surgiu nos grupos de discussão realizados em Lisboa e em Viseu, sendo que as várias participantes referiram que saíam para conviver - «falar», «conhecer pessoas novas», para «escapar à rotina» e para dançar.

Quando questionadas acerca das diferenças de género que percecionavam em dinâmicas de diversão noturna, referiram que consideravam que tinham formas de «estar na noite» diferentes das dos homens.

Enquanto o bar e os consumos se calhar chamam mais os homens, a nível de pista de música eu acho que são as mulheres que fazem mais a pista [...] e acho que toda a gente já percebeu que as mulheres dançam mais e quando as mulheres estão na pista a festa está feita. (GD_Lx_P2)

Outras participantes referiram que os homens se localizam mais nas periferias da pista de dança e enquanto as raparigas dançam é possível observar «grupos de rapazes encostados à parede a ver raparigas passar» (GD_Lx_P5).

Uma das participantes referiu que não sentia nenhuma diferença, acrescentando que sempre tinha saído à noite com grupos de homens e era «tratada como um deles», acrescentando «sempre me dei bem com homens porque não sou cheia de salamaleques»(GD_Lx_P1). Esta participante demonstra claramente uma internalização do sexismo ao atribuir características negativas às mulheres que saem à noite e ao considerar que a igualdade se traduz na adesão às dinâmicas comportamentais tipicamente masculinas.

Em relação à publicidade presente em contextos festivos, a grande maioria das participantes considerou que «a parte sensual e sexual feminina é muito explorada na noite, sempre foi» (GD_Viseu_P4). As participantes de ambos os grupos de discussão identificaram a «Noite da Mulher» como a prática de publicidade sexista mais comum. Para elas estes eventos são «um chamariz»(GD_Lx_P2), «época de caça aberta» (GD_Lx_P1), «no fundo é como a pornografia, é feita para homens» (GD_Lx_P3), «procura de acasalamento» (GD_Viseu_P2). No entanto, identificaram contextos onde estas práticas eram mais comuns, nomeadamente bares e discotecas com música mais comercial e contextos académicos. Em ambos os grupos de discussão, foi referido que paisagens sonoras como o trance oferecem um lazer mais igualitário, quer pelo tipo de frequentador/a, quer pela música, e que, em geral, estas festas permitem uma «transcendência da música e dos próprios consumos» e tornam as pessoas «mais libertas» (GD_Lx_P4). Esta crença foi identificada anteriormente em outros estudos que demonstraram que os clubes mainstream (comerciais) aparecem mais ligados a uma conceptualização da mulher como «objeto sexual» enquanto os contextos mais underground (alternativos) apresentam uma maior igualdade entre homens e mulheres e permitem, a estas últimas, expressar uma identidade sexual mais positiva (Lopes et al. 2011; Huton apud Gunby et al. 2016; Noctambul@s 2016). Este facto relaciona-se muito possivelmente com as características ambientais desses mesmos contextos. Os contextos mains- 
tream investem, frequentemente, na divulgação de conteúdos sexistas e hipersexualizados como é o caso da «Noite da Mulher ${ }^{3}$ », publicidade para promover o consumo de determinadas bebidas alcoólicas, o dress code e os próprios temas das músicas, algumas com conteúdos sexualmente violentos (Gunby et al. 2016). Estes conteúdos produzem um imaginário que remete os/as seus/suas frequentadores/ as para determinado tipo de dinâmicas e relações interpessoais que podem resultar em flirts e interações sexuais consentidas ou não.

Quando questionadas acerca da ocorrência de situações de violência sexual em contextos festivos, apenas uma mulher referiu ter sido vítima de uma tentativa de violação. Todas as outras referiram já ter assistido ou ter conhecimento de casos de amigas ou conhecidas que tinham sido abusadas sexualmente nestes ambientes. No entanto, durante os grupos de discussão, foi possível verificar que todas sentiam e normalizavam situações de assédio e inclusive tinham as suas estratégias para lidar com elas.

Quando vamos ao X [discoteca em Lisboa] digo logo às minhas amigas para não estabelecerem contacto visual. [GD_Lx_P2]

Em relação a saídas, especificamente saídas de mulheres, há sempre aqueles abutres, aqueles homens que saem para procurar mulheres. (GD_Lx_P5)

Há sempre aquele cola que encosta atrás ou está sempre a querer pagar uma cerveja e tu não queres e ele insiste... (GD_Viseu_P6)

O facto de as participantes dos grupos de discussão referirem com bastante naturalidade, e até com humor, que já passaram por situações de assédio sexual em contextos festivos («roços», insistências, comentários, perseguições), revela que, para elas este tipo de comportamento nestes contextos é normal. Comentários como «mas isso é que é a noite» (FG_Lx_P4) demonstram a aceitação de que sair à noite implica, em algum momento, ser assediada sexualmente. Outros/as autores/ as identificaram também que situações de assédio sexual são particularmente prevalentes em contextos festivos (Barros 2016; Gunby et al. 2016; Noctambul@s 2016). De acordo com o Observatório Noctambul@s (2016) existe a crença de que as mulheres que frequentam contextos festivos são mais empoderadas e têm uma maior liberdade sexual, sendo esta entendida como disponibilidade sexual e acesso.

Para as mulheres que participaram nos dois grupos de discussão, a liberdade e o acesso a contextos festivos pressupõe assumir o risco de poder ser vítima de violência sexual.

Tirando aquela parte de podermos ser vítimas numa situação violenta ou coisa que o valha, não consigo fazer essa distinção [diferenças de género em contextos festivos], acho que é igual. (GD_Lx_P3)

Noites temáticas em que as mulheres entram gratuitamente e têm direito a bebidas a custo zero, enquanto os homens pagam a entrada e os seus consumos. 
Eu sempre tive a preocupação com a cena de ser mulher. Por ser mulher tenho de estar mais viva, posso consumir o que quiser, mas tenho de estar mais viva. (GD_Lx_P1)

Em ambos os grupos de discussão as mulheres consideraram que os homens são mais «descontrolados», e que o seu comportamento abusivo «tem que ver com a testosterona, é uma questão biológica» (GD_Lx_P2). Esta crença denuncia a adesão a mitos da violação: enquanto a mulher assume o risco de poder vir a ser agredida, o comportamento abusivo ou agressivo dos homens é desculpabilizado, aludindo a uma hipersensibilidade masculina que se traduz numa menor capacidade de resistir aos seus impulsos sexuais (Bohner et al. 2009; Noctambul@s 2017).

Em caso de violência sexual, a desigualdade de género traduz-se também na culpabilização da vítima, que «se pôs a jeito» ou não se protegeu o suficiente.

Eu já tive colegas minhas, ao meu lado, a fingirem-se de bêbedas para conseguirem estar com um rapaz que não conheciam de lado nenhum [...], mas não sei até que ponto seremos assim tão inocentes [...], miúdas a vestirem uma minissaia para irem a uma discoteca, acho que nos sujeitamos muito a isso. (FG_Viseu_P1)

Mas eu comecei a perceber que isso tem que ver não com a moca com que tu estejas ou porque bebeste muito, tem muito que ver com a personalidade das pessoas, porque eu já tive que defender amigas minhas também porque são aquelas pessoas que não conseguem reagir... (GD_Lx_P1)

Nas suas narrativas, as mulheres de ambos os grupos de discussão denunciam novamente uma clara adesão aos mitos da violação, ao considerarem que há um determinado tipo de mulheres que, pela sua roupa, consumos e falta de reação, pode ser potencialmente vítima de situações de violência sexual (Mardorossian 2002; Bohner et al. 2009).

Finalmente, foram identificadas algumas diferenças nos discursos das mulheres que participaram nos grupos de discussão em Lisboa e em Viseu. As participantes no grupo de discussão implementado em Viseu tenderam a distanciar-se mais dos padrões de consumo que atribuíam aos homens, referindo que em alguns contextos mais rurais ainda sentiam que não era bem-visto o consumo de álcool por mulheres. «Esses cafés são mais frequentados por homens, e se entro e peço uma mini ficam logo todos a olhar de lado» (GD_Viseu_P3). As participantes do grupo de discussão de Lisboa referiram sentir poucas diferenças de género no que diz respeito ao acesso a contextos festivos e ao consumo de SPA e algumas assumiram «beber mais que eles»(FG_Lx_P2), «eles já estão todos mortos e eu ainda estou bem» (FG_Lx_P5), «acho que sou mais resistente» (FG_LxP3). No entanto, por diversas vezes surgiram, nos discursos das participantes de ambos os grupos de discussão, as diferenças de género que se traduziam na necessidade de estas controlarem os seus consumos e de se protegerem. 


\section{A relação entre consumo de SPA e violência sexual em contextos festivos}

Tradicionalmente, a grande maioria dos utilizadores problemáticos de heroína eram homens e, por esse motivo, os estudos acabaram por oferecer uma visão androcêntrica desta realidade, invisibilizando as especificidades deste tipo de consumos nas mulheres (Romo 2004; OEDT 2006). Mais recentemente, alguns estudos têm vindo a explorar o consumo de SPA a partir da perspetiva da mulher, considerando as suas especificidades, os seus papéis, perceções, expectativas sociais e riscos (Romo 2004, Benoit e Dambélé 2015).

O álcool é a SPA mais associada a situações de violência sexual e, contrariamente a outras, é uma substância socialmente aceite e encorajada em alguns contextos (Dawgert 2009), como é o caso dos contextos festivos. A este nível, importa sublinhar que a relação entre consumo de SPA e agressões sexuais é multidimensional. A investigação demonstra que, no que diz respeito ao álcool, o seu consumo não é um fator causativo por si só, mas que os seus efeitos cognitivos e farmacológicos interagem com características individuais (personalidade, crenças acerca do consumo de álcool e sexo), e normas sociais e culturais sobre género. Neste sentido, para compreender a relação entre álcool e agressões sexuais é importante introduzir questões contextuais, principalmente quando se pretendem implementar medidas preventivas (Wall e Quadara 2014). A violência sexual em contextos festivos deve ser observada a partir de uma perspetiva de género, que considera que não é o consumo de SPA que justifica estes comportamentos, mas, sim, a construção social do masculino e do feminino. A permissividade para com as situações de violência sexual presente nestes contextos deve-se fundamentalmente aos seus códigos e mensagens subliminares relacionados com os papéis de género. Se algumas situações de assédio sexual ocorressem noutros contextos seriam muito mais recriminadas e punidas (Noctambul@s 2016).

Vários estudos reportam diferenças na perceção de homens e mulheres utilizadores/as de álcool: embriaguez, perda de controlo e exagero são características associadas aos homens consumidores de SPA (Sznitman 2007; Østergaard 2007). As mulheres que adotam estes padrões de consumo são mais facilmente consideradas desviantes, «fáceis», vulneráveis e com maior disponibilidade sexual (Sznitman 2007; Gunby et al., 2016; Noctambul@s 2016). No seu estudo, Sznitman (2007) conclui que as mulheres se sentem constantemente observadas nos seus consumos de álcool e procuram não exceder os seus limites para manter a postura e o autocontrolo que são esperados delas. Esta necessidade de autocontrolo e de moderação foi explícita e consensual entre todas as participantes nos grupos de discussão.

Eu acho que há diferença, na parte das mulheres, tanto no consumo de álcool como substância. Por exemplo, vamos a uma discoteca, há uma miúda que está bêbeda, cai, já é logo ali gozada, se for um rapaz, já é fixe estar bêbedo, porque é uma coisa normal. (GD_Viseu_P5) 
Eu olho para uma mulher a vomitar-se tenho uma sensação diferente do que se visse um homem a vomitar, porque um homem não é tão indefeso. (GD_Viseu_P3)

Eu posso estar tribêbaba e tenho sempre ali o pezinho, a noção do que estou a fazer... (GD_Lx_P2)

Esta tensão entre a procura de autonomia e consumo recreativo e o receio da perda de controlo foi também identificada por Lopes et al. (2010), no seu estudo sobre mulheres frequentadoras de contextos festivos. Analisando os discursos das participantes nos grupos de discussão, é possível perceber que estas mulheres interiorizam o que Mardorossian $(2002,759)$ define como autopanoticismo, «um sistema individualizado e interiorizado de vigilância, pelo qual, cada mulher se torna vigilante de si própria». Aqui reproduzem-se novamente assimetrias de género, pois é expectável que as mulheres se controlem e autovigiem enquanto se desconsidera o agressor.

Starfelt et al. (2015) concluíram que alguns dos efeitos associados ao consumo de álcool facilitam interações com potenciais agressores/vítimas, nomeadamente: o aumento de confiança, a expressão de características interpessoais (por exemplo, agressividade, sociabilidade, sedução) e emocionais (por exemplo, alegria, tristeza), a capacidade de analisar situações e de decidir, a desinibição, dificuldade nos processos de negociação sexual (comunicação verbal e não-verbal), dificuldade na identificação de riscos. No caso dos agressores, estar sob o efeito de álcool ou outras SPA pode interferir com os mecanismos físicos e psicológicos que agem como inibidores da agressão. Por esse motivo, o consumo de álcool e/ou outras SPA pode ser usado como desculpa, mas também como parte de um plano (Noctambul@s 2016).

Eles pensam lá nisso [proteger mulheres alcoolizadas]! Querem lá saber eles, querem é tirar o proveito. (GD_Lx_P2)

Eu acho que a pessoa que tenta também se apercebe disso, vê se é uma pessoa mais frágil ou não, ou se vale a pena. (GD_Lx_P5)

A este nível, surgem novamente desigualdades de género. «Ter realizado um consumo voluntário prévio entende-se como uma atenuante para a culpa do agressor, mas, em troca, julga-se como um agravante da culpa da vítima de violência sexual» (Noctambul@s 2016, 29). Esta culpabilização da vítima apareceu também bem demarcada e interiorizada nos discursos das mulheres que participaram nos grupos de discussão. Para estas mulheres, ser «cuidadosa» e manter algum grau de consciência durante os seus consumos são responsabilidades que assumem na sua vivência de contextos festivos. As formas como se protegem e autocontrolam variam, mas a grande maioria destas mulheres assume evitar que os seus consumos lhes tirem a «consciência», tentando controlar as situações, ter cuidado com as bebidas que lhes oferecem, não entrar em carros de desconhecidos, gerir os flirts. 
Eu lembro-me que quando comecei a consumir [...], na altura eram mesmo pastilhas e das boas, ficava tudo in love e não sei quê e eu própria tive algumas situações. Nunca me senti ameaçada ou assim porque acabei por conseguir sair delas, ou seja, acabei eu por ter sempre de qualquer forma o controle sobre elas. (GD_Lx_P2)

Eu acho que tive sorte, que tive sempre muita sorte. (GD_Lx_P3)

Sempre que me dão alguma coisa tenho de ter a mínima confiança, sempre tive a pancada das bebidas minadas, «dá-me a bebida, mas é à minha frente». (GD_Lx_P1)

Em ambos os grupos de discussão as participantes culpabilizaram as suas pares que sofreram atos sexuais não consentidos, referindo mesmo que «elas querem ser minadas» (FG_Viseu_P4) e «muitas mulheres usam a desculpa de que estão bêbadas [para se envolverem sexualmente com alguém]» (GD_Lx_P4).

De acordo com o Observatório Noctambul@s, a existência de uma situação de violência sexual é indiscutível nos casos de submissão química premeditada - a vítima não tem conhecimento de que está a consumir uma substância psicoativa colocada pelo agressor, por exemplo, na sua bebida. No caso de situações de violência sexual que ocorrem após consumos voluntários de SPA, surgem dúvidas em relação ao consentimento. É nestas situações que o conceito «consentimento» não é claro no imaginário coletivo, o agressor não considera que esteja a cometer um crime sexual e a vítima autoculpabiliza-se (Noctambul@s 2016). Através de um questionário online $(\mathrm{n}=1079)$, Gunby et al. (2012) verificaram que um terço dos/as respondentes $(n=329)$ relataram terem experienciado, sob o efeito de álcool, relações sexuais não consentidas, sendo que $83 \%$ eram do sexo feminino. Adicionalmente, cerca de metade dos/as respondentes, principalmente do sexo feminino, consideram que o consentimento se expressa oralmente e que os respondentes masculinos não acreditavam tanto que os efeitos do álcool pudessem afetar a capacidade de decidir. A respeito do consentimento sexual, O'Byrne et al. (2008) consideram que o argumento da «falta de comunicação» serve para desculpabilizar o agressor por não ter, alegadamente, percebido claramente a recusa, principalmente quando esta não é verbal e explícita. Esta ênfase na falta de comunicação responsabiliza a vítima por não ter sido clara e manifesta na sua recusa e reproduz crenças associadas aos mitos da violação que urgem serem desconstruídas. Ventura (2015) avaliou o papel do consentimento na evolução dos crimes sexuais no Código Penal, concluindo que, na ausência de violência, coação sexual ou resistência física, persistem dúvidas sobre a veracidade do depoimento da mulher, assentes no mito das falsas denúncias. Esta falta de credibilidade atribuída à vítima traduz uma desvalorização generalizada da palavra feminina, tendo a vítima de apresentar provas irrefutáveis e expor publicamente a sua dor para confirmar a sua vitimação sexual. «É a legalização da ideia de que há mulheres que não são verdadeiramente violadas, tendo contribuído (in)voluntariamente para o efeito», relativizando-se assim a culpa do agressor (Ventura 2015: 79).

É importante destacar também que as agressões sexuais relacionadas com o consumo voluntário de álcool podem ser um fator revitimizante. Não ter uma 
clara memória do que aconteceu pode provocar na vítima autoculpabilização, que a leva a não denunciar a situação e a isolar-se (Dawgert 2009). As vítimas podem também vir a sofrer stress pós-traumático, sentimentos de raiva, vergonha e negação, dificuldades no relacionamento interpessoal, uso de SPA, depressão e suicídio. As consequências físicas mais comuns são ferimentos, infeções sexualmente transmissíveis e gravidezes indesejadas (Gunby et al. 2012).

Finalmente, interessa sublinhar que, independentemente dos padrões de consumo de SPA das mulheres, os únicos agentes responsáveis pela violência sexual são os agressores e são eles que devem abster-se de o fazer.

\section{Podem os contextos festivos ser ambientes educativos e preventivos de vio- lência sexual?}

Pelo descrito, é fundamental implementar, em contextos festivos, iniciativas educativas e preventivas que permitam desconstruir as crenças e imaginários que legitimam o sexismo e a violência sexual. Para isso, é necessário capitalizar o potencial educativo destes contextos e colocá-lo ao serviço da prevenção. Aqui a educação informal é a melhor abordagem para promover iniciativas que previnam agressões sexuais. De acordo com Canário, a educação informal «corresponde a todas as situações potencialmente educativas, mesmo que não conscientes, nem intencionais, por parte dos destinatários, correspondendo a situações pouco ou nada estruturadas e organizadas» $(2008,65)$. Em contextos festivos, o trabalho educativo a desenvolver com os seus frequentadores deve focar-se em temas que promovam interações sexuais consentidas e não-abusivas.

Tradicionalmente, as campanhas de prevenção de agressões sexuais na noite são dirigidas a mulheres. Muitas destas campanhas são sexistas por assentarem numa «moralidade da precaução» (Burges et al. apud Gunby et al. 2016). Um exemplo é a campanha «Control Tonight», financiada pela Pensylvania Liquor Control Board para prevenir o consumo de álcool, onde um dos posters de sensibilização refere «Ela não queria, mas não conseguiu dizer que não», com uma imagem onde se veem as pernas da vítima, que está deitada no chão, com as suas cuecas pelos tornozelos (Andric 2012). A mesma campanha tem ainda dicas de prevenção que assentam na responsabilização das mulheres pela sua proteção, excluindo o principal responsável por essa situação - o agressor (Andric 2012; Warren 2015; Gunby et al. 2016). Este exemplo sublinha a necessidade de evitar campanhas sexistas e revitimizantes e investir em ações de apoio às vítimas e ações de educação que visem os principais responsáveis pela violência sexual.

Gunby et al. (2016) avaliaram o impacto de uma campanha-piloto de prevenção de violações que teve a duração de três meses e cujo público-alvo foram homens frequentadores de contextos festivos entre os 18 e os 24 anos. Foi promovida pelo Município de Liverpool, e tinha três objetivos: a) dar a conhecer o enquadramento legal do consentimento; b) informar que relações sexuais com alguém 
incapaz de consentir é violação e c) reduzir e prevenir a incidência de violações e abusos sexuais e redirecionar as vítimas para serviços de apoio. Esta campanha consistiu em posters informativos com a mensagem «Não responde? Não consegue consentir - sexo sem consentimento é violação», explicando o enquadramento legal da violação. Estes posters foram estrategicamente colocados nas casas de banho masculinas de bares e discotecas, universidades e associações de estudantes. A campanha foi ainda divulgada online nas redes sociais e num anúncio na rádio. Os dados de impacto desta campanha foram recolhidos através de questionários $(n=321)$ e 6 focus groups $(n=41)$, com representantes da população-alvo. Os participantes consideraram a campanha, a simplicidade da sua mensagem e o contexto de implementação pertinentes. No entanto, apesar da sua ampla disseminação, apenas alguns referiram conhecê-la. Para os autores, esta invisibilidade pode relacionar-se com o facto de, nesses contextos, haver uma sobreposição de imagens e mensagens publicitárias sexualizadas ou porque, em contextos de diversão, os jovens se distanciam de mensagens focadas em riscos. Apesar disso, os/as autores/as mantêm que os contextos festivos são estratégicos para este tipo de campanha.

Adicionalmente, para desincentivar potenciais agressores, é relevante investir em iniciativas de sensibilização e educação não-formal e informal que tornem claro que: a) o consentimento é muito mais do que a ausência de resposta e definam o que é um comportamento sexual aceitável e não aceitável; b) o álcool não desculpabiliza agressões sexuais; c) desconstruam a crença geral de que as alegações de agressão sexual são falsas, fornecendo informação factual que contradiga estes mitos (Gunby et al. 2012; Wall e Quadara 2012). O Observatório Noctambul@s (2016) sugere: dar mais visibilidade aos abusos sexuais menos graves; promover uma má imagem do abusador; corresponsabilizar os espaços de diversão noturna e sensibilizar o seu staff para a identificação de situações de assédio e abuso sexual; responsabilizar os agressores pelos seus comportamentos sem usar o consumo de SPA como desculpa; reforçar a necessidade de consentimento. No seu relatório de 2017, destacam ainda a necessidade de as autarquias se responsabilizarem pela promoção de campanhas neste âmbito; o papel dos média para desconstruir a normalização destes comportamentos e dar-lhes visibilidade; de implicar também o setor privado da diversão noturna para reduzir comunicação e imagens sexistas e implementar protocolos de atuação em caso de violência sexual em contextos festivos; e interpelar também eventuais testemunhas abraçando uma lógica de responsabilidade coletiva.

Finalmente, e pelo exposto, pode-se assumir que intervir em contextos festivos para prevenir agressões sexuais mais ou menos graves pode constituir-se como «reforço deliberado do potencial educativo nos ambientes ou territórios em que as pessoas estão inseridas» (Canário 2008, 80) e em que os comportamentos acontecem. 


\section{Considerações finais}

À semelhança do que acontece noutros contextos, os contextos festivos impõem variadas tensões às mulheres, que se vêm obrigadas a conciliar a experimentação e procura de liberdade (neste caso a vivência destes contextos e consumo de SPA) com os papéis sociais que lhes são atribuídos. Também nestes contextos, há uma preocupante prevalência e normalização de situações de violência sexual que urge desconstruir. O uso de SPA surge como agravante das desigualdades de género, visto que, socialmente, o mesmo tipo de consumo desculpabiliza o comportamento do agressor ao mesmo tempo que culpabiliza a vítima pela sua falta de autocontrolo, reproduzindo mitos da violação. A análise dos grupos de discussão implementados em Lisboa e em Viseu demonstrou que: há diferenças de género na vivência de contextos festivos e no uso de SPA, as situações de assédio sexual são trivializadas e encaradas como parte integrante das saídas à noite, e o autocontrolo surge como uma responsabilidade feminina para garantir a sua segurança. Surgiram também discursos particularmente penalizadores das mulheres que não se protegem e que acabam por ser vítimas de violência sexual, perpetuando mitos da violação. Neste âmbito, interessa sublinhar que o consumo de SPA desvia a atenção do cerne do problema - não são os usos de SPA que justificam ou desculpabilizam a violência, o único responsável por estes comportamentos é o agressor.

Os contextos festivos podem e devem ser intervencionados para a promoção de uma noite mais igualitária. Para além de ações educativas e preventivas que contrariem a normalização da violência sexual nestes ambientes, devem ser pensadas ações específicas para dissuadir potenciais agressores e corresponsabilizar potenciais espectadores/as. Devem também envolver-se os/as promotores/as e colaboradores/as destes ambientes bem como produtores/as e distribuidores/as de bebidas alcoólicas na implementação de ações de prevenção ambiental que promovam uma cultura de diversão noturna mais segura e não sexista.

Por último, consideramos que seria importante realizar grupos de discussão sobre os mesmos temas também com homens para aceder às suas narrativas, e proceder a um estudo epidemiológico para identificar, a nível nacional, o alcance e contornos das situações de violência sexual nestes contextos.

\section{Referências bibliográficas}

Andric, Andrea. 2012. «When anti-drinking campaigns become victim blaming campaigns». Lip Magazine, 22 de janeiro. Disponível em http://lipmag.com/culture/when-antidrinking-campaigns-become-victim-blaming-campaigns/ [Consultado em 14 de maio de 2017].

Barros, Carolina Mara. 2016. «A agressão sexual em contextos festivos e o consumo de substâncias psicoativas». Dissertação de Mestrado em Psicologia, Faculdade de Psicologia e Ciências da Educação da Universidade do Porto. 
Benoit, Thérèse, e Sayon Dambélé. 2015. Violence experienced or perpetrated, and psycho-active substance use among women in Europe and in the Mediterranean region: Literature review and identification of lines of research. Pompidou Group of the Council of Europe. Disponível em https://www.coe.int/en/web/pompidou/activities/gender/gender-dimension-publications

Bohner, Gerd, Friederike Eyssel, Afroditi Pina, Frank Siebler, e Tendayi Viki. 2009. «Rape myth acceptance: Cognitive, affective, and behavioural effects of beliefs that blame the victim and exonerate the perpetrator». In Rape: Challenging Contemporary Thinking, edited by Miranda A.H Horvath and Jennifer M. Brown, pp. 17-45. Londres: Willan. DOI: $10.4324 / 9781843927129$.

Canário, Rui. 2008. Educação de Adultos: um campo e uma problemática. Lisboa: Educa.

Dawgert, Sarah. 2009. Substance use and sexual violence: Building prevention and intervention responses. Pennsylvania Coalition Against Rape. Disponível em http://www.pcar.org/ sites/default/files/pages-pdf/substance_use_and_sexual_violence.pdf [Consultado em 15 de abril de 2017].

Goulding, Christina, e Avi Shankar. 2011. «Club culture, neotribalism and ritualised behavior». Annals of Tourism Research 38 (4): 1435-1453. DOI: https://doi.org/10.1016/j. annals.2011.03.013

Gunby, Clare, Anna Carline, Mark A. Bellis, e Caryl Beynon. 2012. «Gender differences in alcohol-related non-consensual sex; cross-sectional analysis of a student population». BMC Public Health 12 (216): 1-12. DOI: https://doi.org/10.1186/1471-2458-12-216

Gunby, Clare, Anna Carline, e Stuart Taylor. 2016. «Location, Libation and Leisure: An examination of the use of licensed venues to help challenge sexual violence». Crime, Media, Culture 13 (3): 315-333. DOI: https://doi.org/10.1177/1741659016651751

Hollands, Robert G. 1995. Friday Night, Saturday Night: Youth Cultural Identification in The Post-Industrial City. Newcastle Upon Tyne: University of Newcastle. Department of Social Policy.

Lopes, João Teixeira (coord.), Pedro dos Santos Boia, Lígia Ferro, e Paula Guerra. 2011. Género e Música de Dança. Experiências, Percursos e «Relatos» de Mulheres Clubbers. Lisboa: Comissão para a Cidadania e a Igualdade de Género.

Noctambul@s. 2016. Informe 2014/2015. Fundácion Salud y Comunidad. Disponível em http://www.drogasgenero.info/noctambulas/informes/\#fb1=1 [Consultado em 4 de abril de 2017].

Noctambul@s. 2017. Tercer Informe Anual 2015/2016. Disponível online em: http://www. drogasgenero.info/noctambulas/informes/\#fb1=1 [Consultado em 10 de abril de 2017].

Mardorossian, Carine M. 2002. «Toward a New Feminist Theory of Rape.» Signs 27 (3): 743775. DOI: https://doi.org/10.1086/337938

O’Byrne, Rachael, Susan Hansen, e Mark Rapley. 2008. «"If a Girl Doesn't Say 'no'...": Young Men, Rape and Claims of 'Insufficient Knowledge'». Journal of Community $\mathcal{E}$ Applied Social Psychology 18 (3): 168-193. DOI: https://doi.org/10.1002/casp.922

OEDT - Observatório Europeu das Drogas e Dependências. 2006. Annual Report 2016, Selected Issues 2: A gender perspective on drug use and responding to drug problems. Lisboa: European Monitoring Centre for Drugs and Drug Addiction. Disponível em http://www.emcdda. europa.eu/html.cfm/index34880EN.html [Consultado em 23 de setembro de 2016].

Østergaard, Jeannete. 2007. «Mind the gender gap! When boys and girls get drunk at a party». Nordic Studies on Alcohol and drugs 24 (2), 127-148. DOI: https://doi.org/10.1177/ 145507250702400209

Romo, Núria. 2004. «Género y uso de drogas: la invisibilidad de las mujeres». Monografías Humanitas 5: 69-83. Disponível em http://hdl.handle.net/10481/22315 
Sottomayor, Maria Clara. 2015. «A Convenção de Istambul e o novo paradigma da violência de género». ex aequo 31: 105-121. DOI: https://doi.org/10.22355/exaequo.2015.31.08

Starfelt, Louise C., Ross McD. Young, Gavan R. Palk, e Katherine M. White. 2015. «Young Australian adults' beliefs about alcohol's role in sexual aggression and victimization». Culture, Health \& Sexuality: An International Journal for Research, Intervention and Care, 17 (1): 104-118. DOI: https://doi.org/10.1080/13691058.2014.950984

Sznitman, Sharon Rödner. 2007. «Drugs and gender: a contradictory project in interviews with socially integrated men and women who use drugs». Nordic Studies on Alcohol and Drugs 24 (2): 107-126. DOI: https://doi.org/10.1177/145507250702400210

TNS Opinion \& Social. 2016. «Gender-based violence». Special Eurobarometer Report 449. Disponível em http://ec.europa.eu/COMMFrontOffice/publicopinion/index.cfm/Survey/ getSurveyDetail/instruments/SPECIAL/surveyKy/2115 [Consultado em 12 de março de 2017].

Valente, Helena, Cristiana Vale Pires, e Helena Carvalho. 2018. «Nightlife as an educational setting: the harm reduction perspective». In Exploring Nightlife: Space, Society and Governance, editado por Adam Eldridge e Jordi Nofre. Londres: Rowman and Littlefield.Ventura, Isabel. 2015. «Um corpo que seja seu - podem as mulheres [não] consentir?» ex æquo 31: 75-89. DOI: https://doi.org/10.22355/exaequo.2015.31.06

Wall, Liz, e Antonia Quadara. 2014. «Under the influence? Considering the role of alcohol and sexual assault in social contexts». ACSSA Issues, 18: 1-22. Disponível em https:// aifs.gov.au/publications/under-influence

Warren, Rossalyn. 2015. «We asked an expert what was wrong with these anti rape posters». BuzzFeedNews, 30 de abril. Disponível em https://www.buzzfeed.com/rossalynwarren/we-asked-an-expert-what-was-wrong-with-these-anti-rape-poste?utm_term=. ocvNPq1Pj\#.moGG8w98k [Consultado em 15 de abril de 2017].

Cristiana do Vale Pires. Licenciada em Psicologia (FPCE-UP), Mestre em Antropologia: Globalização, Migrações e Multiculturalismo (ISCTE-IUL) e doutoranda em Antropologia (ISCTE-IUL). Desde 2009 que trabalha na APDES em projetos de intervenção em contextos festivos. Tem também colaborado e coordenado projetos nacionais e internacionais na área dos consumos recreativos de substâncias psicoativas e redução de riscos. Integra como colaboradora as unidades de investigação CRIA e RECI.

Raquel Pereira. Licenciada em Antropologia (ISCTE-IUL), Mestre em Antropologia: Globalização, Migrações e Multiculturalismo (ISCTE-IUL) e doutoranda em Antropologia (ISCTE-IUL). Trabalhou num projeto de intervenção em contextos festivos CHECK!N Lx - em 2014 e 2015. Atualmente é bolseira de investigação em Antropologia (ISCTE-IUL).

Helena Valente. Licenciada em Psicologia (FPCE-UP), pós-graduada em Direitos Humanos (FD-UM) e doutoranda em Psicologia (FPCE-UP). Desde 2007 que trabalha em projetos de intervenção em contextos festivos. Tem também colaborado e coordenado projetos nacionais e internacionais na área dos consumos recreativos de substâncias psicoativas e redução de riscos. Atualmente é bolseira de investigação (FPCE-UP) e integra a unidade de investigação RECI. 
Helena Moura. Licenciada e doutorada em Psicologia (FPCE-UP). Trabalhou na área do HIV/SIDA e desde 2013 que trabalha na APDES, desenvolvendo atividades de investigação na área do consumo de substâncias psicoativas e do trabalho sexual. Integra a unidade de investigação RECI.

Artigo recebido em 3 de julho de 2017 e aceite para publicação em 25 de março de 2018. 